\title{
Neural Network Web-Based Human Resource Management System Model (NNWBHRMSM)
}

\author{
Raphael Olufemi AKINYEDE ${ }^{1}$ and Oladunni Abosede DARAMOLA ${ }^{2}$ \\ ${ }^{12}$ Department of Computer Science, \\ The Federal University of Technology, P.M.B 704, Akure, \\ Ondo-State, Nigeria \\ E-mail:femi_akinyede@yahoo.com
}

\begin{abstract}
As business activities are becoming increasing globally and as numerous firms expand their operations into overseas markets, there is need for human resource management (HRM) to ensure that they hire and keep good employees. From ages, firms/organizations have been having great problems in getting the right professionals into appropriate jobs and training. This research focuses at exploiting information technology in order to overcome these problems. The system, which is a network of inter-related processes, collects data from applicants through a web-based interface and matches with appropriate jobs. This prevents the frustration and some other problems inherent in the manual method of job recruitment, which is the traditional unstructured interview and knowledge based method for matching applicants to jobs. The proposed system is a neural network web-based human resource management system model running on Internet Information (IIS) server with capabilities for Active Server Page (ASP) and Microsoft Access; while Hypertext Markup Language (HTML) are used for authoring web pages. Finally, the system can run on the minimum Pentium machines with Windows XP operating system.
\end{abstract}

Keywords: Human resource management, Knowledge base (KB), Inference engine (IE), Decision support system (DSS), and Neural network.

\section{1 \\ OVERVIEW OF HUMAN RESOURCE MANAGEMENT SYSTEM}

According to Encarta (2012), it was reported that businesses rely on effective human resource management (HRM) to ensure that they hire and keep good employees and that they are able to respond to conflicts between workers and management. HRM specialists initially determine the number and type of employees that a business will need over its first few years of operation. They are then responsible for recruiting new employees to replace those who leave and for filling newly created positions. The understanding of human resource management is important to anyone who works in an organization; and wherever people gather to work, personnel issues become important, such issues like decision making concerning recruitment, living, compensation, performance evaluation, employee discipline, promotions and transfer are of great and paramount importance. The personnel in human resource management department must understand all the rules and regulations guiding the employees of the firms/organizations; this is very important as it will ensure that their everyday personnel actions are consistent with those policies, to do otherwise is to invite serious problems. As earlier noted, human resource management is concerned with the effective use of people in order to attain organizational goals and enhance the personal dignity, satisfaction, and well-being of employees. But all these functions have been carried out manually using traditional file system although few organizations in Nigeria like Phillip Consulting have gone computerized. For instance, the conventional recruitment exercise involves a process, which starts with a requisition from the Head of each department of an organization who is charged with the responsibility of evaluating, 
monitoring and controlling his departmental budget. The requisition is passed onto the personnel department, whose duty it is to schedule appropriate recruitment, selection, placement and training programs as shown in Figure 1 below.

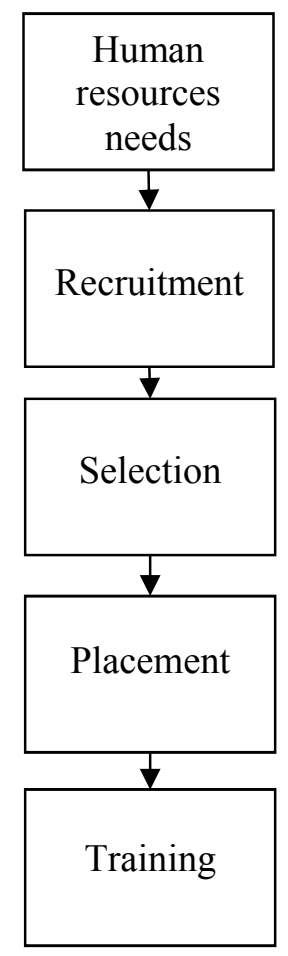

Fig. 1. Human resources model

According to Akinyokun and Uzoka (1998), personnel recruitment's role has changed greatly from one that has been based, largely, on the traditional unstructured interview method to one that is recognized as highly strategic and imperative to the overall success of the organization. It was added that, the role of the HR strategist is now squarely focused on mechanisms to streamline the human resource management (HRM) function in order to contribute to the overall organization's success. Computer, which has remained one of the most powerful tools, has served as an aid to decision making in recent years, mostly because of its efficiency in terms of speed, accuracy, reliability, mass processing, cost and security, among others. Thus, it is not uncommon to find computers being applied in almost every human activity. Presently, a new wave of awareness exists in people as it concerns the use of computers in administrative and qualitative information; it was also confirmed that organizations adopted the use of Management Information System (MIS) and Decision Support Systems (DSS) in their decision process and this has advanced to a web-based human resource management system on the platform of Internet. This research outlines the benefits inherent in web-based human resource management system to streamline processes, outsource administrative activities, improve efficiencies and reduce costs. With its user friendly and technologically advance solution.

In addition, Akinyokun and Uzoka, (1998) also reported that (HRM) involves the use of both quantitative (structural) and qualitative (unstructured) information. Decisions are largely based on institution, principles and experience. Now that the effort to build intelligence into computing system, whereby the computer can be used to process large volumes of quantitative and qualitative information for decision making is becoming reality.

On the whole, HR professionals continue to perform many of the same activities that they did decades ago e.g. training, recruiting, managing, retaining and paying employees. The Internet, however, has had a significant impact on the way the HR professionals accomplish these tasks today, where in the past, HR activities were largely paperintensive and highly manual, the function/process today has been transformed into a sophisticated computer-based process. Technological improvements have allowed HR professionals to spend less time on administrative tasks and more time with employees or employee candidates. It is therefore, not uncommon today, to find some organizations, most especially in developed countries, employing the use of computing system for their personnel recruitment and to an extent, selection exercises. With such a system, the applicant just feed his resumes into the computer wherever he is, by responding to questions on the screen by typing his/her answer, on the keyboard and receives his employment information. Straightaway, the resumes are fed into the organization's central data bank, where they can be quickly processed. HRM is an exciting and dynamic field, even in this age of high information technology; people are still the most important asset to an organization.

Human resource is to support the organizations mission, goals and strategies. The organizations mission is to the purpose to which it is dedicated. For example, the mission of an educational institution is to create and disseminate knowledge. The organizations goals and objectives state what it wants to achieve. To accomplish the organizations goals and support its strategies, human resources objectives and strategies must also be developed.

A business's HRM division also trains or arranges for the training of its staff to encourage 
worker productivity, efficiency, and satisfaction, and to promote the overall success of the business. Finally, human resource managers create workers' compensation plans and benefit packages for employees. The study developed a web-based human resource management system, which will allow applicants to visit the organization employment website before they can enter their data.

Globally, job vacancies are been advertised by the personnel department and such advertisement have the shortcomings which have become the factors fueling the study of this research work, a neural network web-based human resource management system model (NNWBHRMSM). Such shortcomings among others are:

i. Inability to get access to every potential applicant due to the fact that the medium chosen for the advertisement may not be such that is accessible to them. The result of this is that limited number of applicants that are suitable for the jobs would only apply.

ii. Presently in many organizations, most advertisements are only formalities, as relatives of top managers fill the job positions even before the advertisement are out.

iii. Due to high cost of advertisement, job descriptions and specifications are not always well defined to the effect that potential applicants are misinformed about the requirements, duties and remuneration attached with the jobs.

iv. Applicants spend a lot of money producing many copies of application letters and resumes in response to advertisements, which would have been filled online.

v. Many applications use to get lost in transit due to poor performances of our postal services, and in a situation where the selection process is carried out, the applicants

The above stated shortcomings create a situation whereby the organization fails to get right quality and quantity of personnel to fill the available vacant positions. Therefore, a web-based human resource management system was proposed for an effective recruitment process that would take care of these shortcomings of the existing system. Such system will have a data bank of employment opportunities existing for different organizations and a corresponding bank of potential applicants' information obtained via the web. The main objective of the research is to develop a NNWBHRMSM, which will perform the following:

i. enhancing the productivity of the human resource personnel (HRP), thereby improving the productivity of the corporate organization they serve;

ii. reducing time wastages in collecting, sorting and collating of applications from applicants;

iii. determining the potential of each employee in order to ensure individual career growth and personal dignity;

Since the system is client-server activities, it is built on the World Wide Web (WWW) framework. WWW provides a cost effective way of advertising goods, services and vacancies. The research work was carried out by an extensive review of related literature. A thorough study of the current method of recruiting applicants was carried out, and hence, understanding the inadequacies. Afterwards many recruiting organization were visited where personal interviews with staff were conducted. The design of the system was done using Hypertext Markup Language (HTML) for authoring web pages and Microsoft Access Database management system for the design of the database tables. Actives server pages (ASP) running on internet information server was employed for the production and editing HMTL pages. CorelDraw and Corel photo paint were employed for the production and editing of pictures and images. A browser, internet Explorer was used at the client side to interpret contents got from the web server; the browser processes the HMTL and displays the web pages. The web designs runs on Windows XP as the network operating system. Real life data were used to test the system so as to ensure that the design goals were met.

The rest of the paper is structured as follows:Section 2 gave an overview of the related work in the area of study. In sections 3 and 4, we presented the proposed system model and framework for web-based human resource management system (WBHRMS) personnel procurement respectively. However, sections 5 and 6 gave the system implementation and security, while in section 7, we concluded. 


\section{RELATED WORK}

Getting the right professionals into appropriate jobs and training has been the agitation of every organization. For organization to do this, it must understand the scope and policies involved. The personnel department advertises job vacancies and such advertisements are with some shortcomings. The shortcomings created the situation whereby organization fails to get right professionals into the available vacancy. One of the attempts to solve the shortcomings was made in Akintola, (1995). His knowledge based application for matching applicants to job could not be used for long because, apart from being a Microsoft Disk Operating System (MSDOS) based program, it was a single user system that could not be used in a networking environment. To improve on what Akintola did, Uzoka, (1998) developed a knowledge based system for matching applicants to job. Apart from the fact that the system was an MSDOS based (single user) that could not been used in a networking environment, it was not user friendly. Users would need to learn lots of commands before entering into the system. The system also attracts high maintenance because of its relational structure. In addition, it cannot be used in the present world of computing because it could not be launched on the Internet However, since users are geographically distributed, we need a better system and the best online human resources management system program that took care of the shortcomings was developed by Ogunwale, (2005). Ogunwale, (2005) developed a web-based human resources management system, which would have helped organization in making decisions appropriately but the system could not handled employment planning and reports, wages and salaries, etc. Therefore, a neural network web-based human resource management system model which is an improvement on the former ones was proposed. The proposed system will have a data bank of employment opportunities existing from different organizations and corresponding bank of potential applicants obtained through the Internet. The system will help organizations in getting the right professionals into appropriate jobs and training.

\section{THE MODEL}

We consider group of identical workers having the same range of mass $n$. There is also a group of identical organizations having the same type of jobs, $c_{k}$ etc. Organizations use local formal methods such as helpwanted sign posts, television adverts, local or national newspapers. Workers who walk throughout the city, listen to TV or radio adverts or read local newspapers discover at random the information about vacancies. This implies that employed and unemployed workers have exactly the same chance to hear about a vacancy. If the worker is unemployed, he takes the job, $c_{k}$. If he is employed, we assume that he transmits this information within his social network. Therefore, unemployed workers can obtain a job either indirectly through their employed friends (who have heard about a vacant job) or directly. The system can be mathematically model as follows:

Let $c_{1}, c_{2}, \ldots, c_{k}$ be the jobs applicants applied for; $U_{n}$ be the requirements for the job and $J_{m}$ be the qualification and experience of the potential applicant $s_{j}$, such that $i, j, k=1,2,3, \ldots ., \mathrm{n}$. Therefore, $S_{j}, U_{n}$ and $J_{m}$ could be represented as matrices as follows:

$S_{j}=\left\{S_{1}, S_{2}, S_{3}, \ldots \ldots, S_{k}\right\}$, where $\{\mathrm{k}=1,2,3, \ldots . \mathrm{j}\}$

$U_{n}=\left\{U_{1}, U_{2}, U_{3}, \ldots ., U_{t}\right\}$, where $\{\mathrm{t}=1,2,3, \ldots, \mathrm{n}\}$

$J_{m}=\left\{J_{1}, J_{2}, J_{3}, \ldots \ldots, J_{x}\right\}$, where $\{\mathrm{x}=1,2,3, \ldots, \mathrm{m}\}$

The minimum requirements for the job $c_{k}$, is a row vector $U_{k t}=\left[\begin{array}{llll}u_{k 1} & u_{k 2} & \ldots & u_{k n}\end{array}\right]$ and $u_{k n} \subseteq U_{n,} \mathrm{t}=$ $1,2,3, \ldots ., \mathrm{n}$; and for each of the potential candidate $s_{j}$ that applied for the job $c_{k}$, let $a=1,2$, $3, \ldots, \mathrm{p}$ represent additional requirement from which candidates are expected to be examined.. Also, the potential candidates $s_{j}$ 's job requirement for the job $\mathrm{c}_{k}$ is a row vector $j_{i p}=\left[\begin{array}{llll}j_{i 1} & j_{i 2} & \ldots & j_{i m}\end{array}\right]$ and $j_{i m} \subseteq J_{m}, \mathrm{p}=1,2,3, \ldots, \mathrm{m}$.

Here, we use a model to tune the coefficients for the functions $f_{1}, f_{2}, f_{3}, f_{4}$ for the constraints and evaluate their relative importance. The corresponding conditional probability of the occurrence of the job to be offered is

$l^{\prime}=P($ decision $=1 \mid w)=g\left(w^{L} f\right)$

$f(a)=\frac{e^{a}}{1+e^{a}}$

Where $g$ represents the logistic function evaluated at activation $a$. Let $w$ denote weight vector and $f$ the column vector of the importance functions: $f^{L}=\left[f_{1}, \ldots, f_{5}\right]$. Then the "decision" is generated according to the model.

The weight vector $w$ can be adapted using feed forward neural network (FFNN) topology (Schumacher, et al. 1996) and (Biganzoli, et al. 1998). In the simplest case there is one input layer 
and one output logistic layer. This is equivalent to the generalized model with logistic function. The estimated weights satisfy Eq.(iii):

$$
\sum_{i} w_{i}=1,0 \leq w_{i} \leq 1
$$

The linear combination of weights with inputs $\mathrm{f}_{1}, \ldots, \mathrm{f}_{4}$ is a monotone function of conditional probability, as shown in Eq.(i) and Eq.(ii), so the conditional probability of job, $c_{k}$ to be offered can be monitored through the changing of the combination of weights with inputs $f_{1}, f_{2}, f_{3}, f_{4}$. The classification of decision can be achieved through the best threshold with the largest estimated conditional probability from group data. The class prediction of an observation $x$ from group $y$ was determined by

$$
C(x)=\arg \max _{k} \operatorname{Pr}(x \mid l=k)
$$

To find the best threshold we used Receiver Operating Characteristic (ROC) to provide the percentage of detections correctly classified and the non-detections incorrectly classified. To do so we employed different thresholds with range in $[0,1]$. To improve the generalization performance and achieve the best classification, the Multilayer Perceptron with structural learning was employed (Kozma, et al. 1996) and (Ishikawa, 1996).

Such as for each $c_{k}$ and each $s_{j}$ has applied for:

$$
v=\sum \mathcal{W}_{k 2} \quad \text { iff }{ }_{s j}
$$

Job Vacancy:- $f_{1}=\left\{c_{k}\right\}, 1 \leq k \leq 4$

$$
F\left(f_{1}\right) \rightarrow V\left(f_{1}\right)
$$

Where $\mathrm{F}$ is the mapping function between personal data and job vacancy.

$c_{k}=p_{k}$, iff $c_{k}$ is true

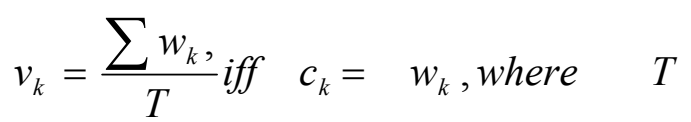

is the total point

Personal data: $f_{2}=\left\{s_{j}\right\}, 1 \leq j \leq 4$

$$
F\left(f_{2}\right) \rightarrow V\left(f_{2}\right),
$$

Where $\mathrm{F}$ is the mapping function between personal data and job vacancy.

$s_{j}=p_{j}$, iff $s_{j}$ is true $v_{j}=\frac{\sum w_{j},}{T}$ iff $s_{j}=w_{j}$, where $T$

is the total point

Academic qualification: $f_{3}=\left\{j_{m}\right\}, 1 \leq j m \leq 4$

$$
F\left(f_{3}\right) \rightarrow V\left(f_{3}\right),
$$

Where $\mathrm{F}$ is the mapping function between personal data and job vacancy.

$j_{m}=p_{m}$, iff $j_{m}$ is true

$v_{j m}=\frac{\sum p_{m},}{T}$ iff $j_{m}=p_{m}$, where $T$

is the total point

Job History: $\quad f_{4}=\left\{u_{n}\right\}, 1 \leq n \leq 4$

$$
F\left(f_{4}\right) \rightarrow V\left(f_{4}\right),
$$

Where $\mathrm{F}$ is the mapping function between personal data and job vacancy.

$u_{n}=p_{n}$, iff $u_{n}$ is true

$v_{n}=\frac{\sum p_{n},}{T}$ iff $u_{n}=p_{n}$, where $T$

is the total point

Note that $s_{j}, c_{k}, j_{m}$ and $u_{n}$ are inputs; and $p_{n}, p_{k}, p_{m}$, $p_{n}=p_{o}$ are points, $y_{n}, y_{k}, y_{m}$ and $y_{n}=y_{i}$ are bias, $\mathrm{v}_{\mathrm{i}}=$ weighs, $\mathrm{o}_{\mathrm{i}}=$ outputs.

$\mathrm{H}$ represent the function that maps $U_{n}$ and $J_{m}$. Then we have

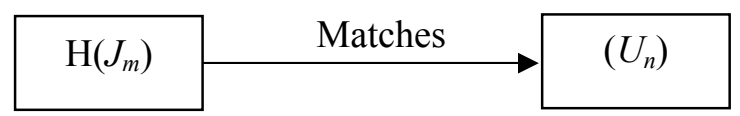

Let $t$ equals total jobs applied for. If $J_{m} \neq U_{n}$ and not end of file (i.e. the applicant qualification does not meet the job requirement), then process $s_{j}=\gamma$. Otherwise $X_{r}=M\left(J_{m}\right), \mathrm{r}=1,2,3 \ldots \ldots, \mathrm{n}$, where $\mathrm{M}$ is a function that returns the list of short listed applicants $s_{t}$.

Therefore, obtain $X_{r}=M\left(J_{m}\right)$.

If $\sum_{t=1}^{r} \gamma(t)<p$, select next $\gamma$ otherwise access the next candidate.

The final shortlisted is expressed as follows 
$f_{-}$shortlisted $= \begin{cases}\frac{1,}{0,} & \text { provided } \sum_{r=1}^{n} X_{r}=p\end{cases}$ where $\sum_{r=1}^{n} X_{r}$ represents the total candidates $s_{t}$ that are qualified for the job $c_{k}$ and the $f_{-}$shorlisted $_{i}$ represents the shortlisted candidates and $p$ represent the maximum requirement for the job $k$, where $J_{m} \subseteq$ $U_{n}$

The description and architecture of the artificial network are hereby given.

One natural way the decision making problem can be addressed is via the tuning the coefficients for the soft constraints. This will largely simplify the architecture, and it saves on both running time and memory. Decision making can also be viewed as a classification problem, for which neural networks demonstrated to be a very suitable tool. Neural networks can learn to make human-like decisions, and would naturally follow any changes in the data set as the environment changes, eliminating the task of re-tuning the coefficients.

Figure 2 above shows the architecture of the feed forward neural network of a web-based human resource management system (WBHRMS). The neural network architectures have three (3) layers. The first layer, which is the only layer exposed to external signals is called the input layer. The layer accepts signal (such as applicant's resume) and transmits it to the neurons in the next layer, which is the hidden layer. Each of these layers is linked to several other hidden layers between the input and output layers of the network. The layer, which may be several layers of hidden nodes, performs a calculation on the signals reaching it and sends a corresponding output signal to other layers. The layer will extracts relevant features or patterns (employees' job specifications) from the received signals. The final outputs are highly processed version of the input, which are then directed to the output layer -the final layer of the network.

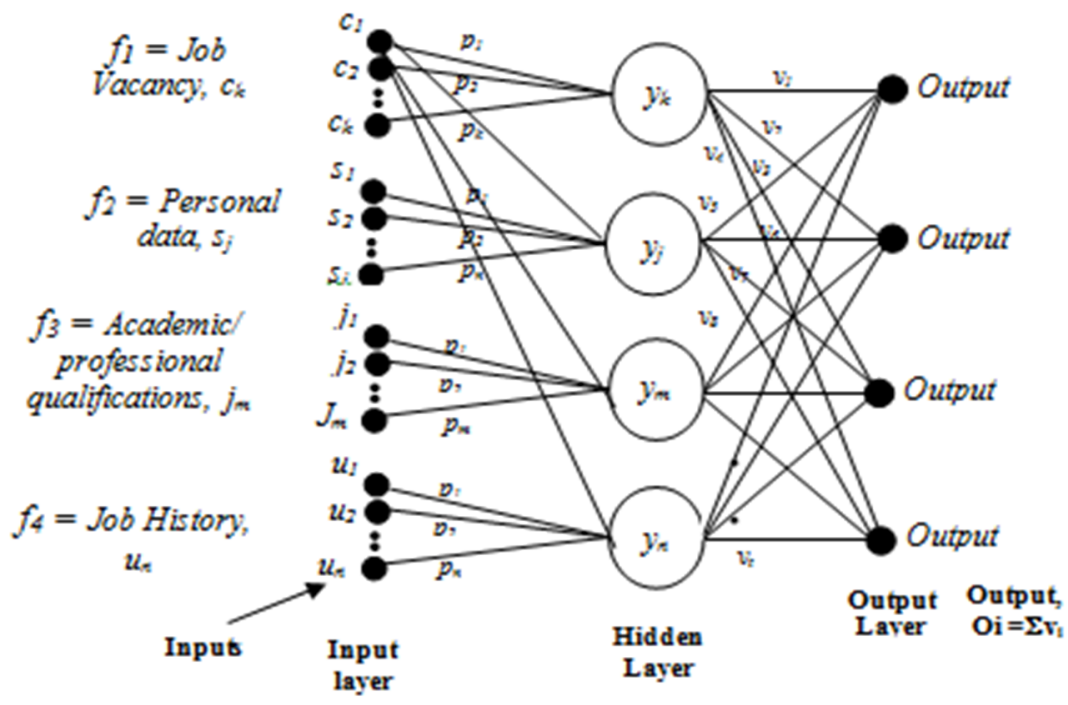

Fig. 2. Artificial neural network model of the WBHRMS

A simplified model of a neuron can easily be simulated by an artificial neuron shown in figure 3 . The variables $s_{j}, c_{k}, j_{m}$ and $u_{n}$ which represent the input line at a particular point in time has one output line each representing the axon of the neuron.

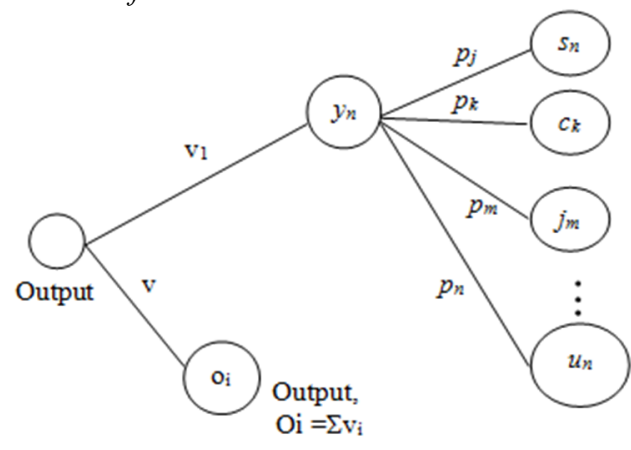

Fig. 3. Final selection for Neural Network Model of the WBHRMS 
The input-output behaviour of the artificial neuron is now by

Test:

$$
\begin{gathered}
f_{n}=\left\{s_{n}, c_{k,} j_{m}, u_{n}\right\}, 1 \leq n \leq 3 \\
F\left(f_{n}\right) \rightarrow V\left(f_{n}\right),
\end{gathered}
$$

where $\mathrm{F}$ is the mapping function between personal data and job vacancy.

$\mathrm{s}_{\mathrm{n}}, \mathrm{j}_{\mathrm{n}}, \mathrm{u}_{\mathrm{n}}=p_{o}$, iff $s_{n,} j_{n} u_{n}$ are true

$v_{n}=\frac{\sum p_{o},}{T}$ iff $s_{n}, j_{n} u_{n}=p_{o}$, where

\section{$T$ is the total point}

The variable $p_{o}$ is called the weight of input line $i$ and represent the synaptic transmission efficiency of the synapse between the final filament of a neuron and the dendrites $i$ of a particular neuron.

\section{FRAMEWORK FOR WEB-BASED HUMAN RESOURCE MANAGEMENT SYSTEM (WBHRMS) PERSONNEL PROCUREMENT THE MODEL}

The framework proposed for web-based personnel procurement is conceptualized in figure 5 and 6 . In this section, we present the relational form of the human resources management conceptual objects. Statistical procedure is used for analyzing the operation and implementation of efficient human resources management system. The system design is aimed at effective and efficient human resources management on the Internet. The global chart of the database design is as shown in fig. 4 .

The major components of the framework are the following, namely: knowledge base, database, inference engine, decision support system

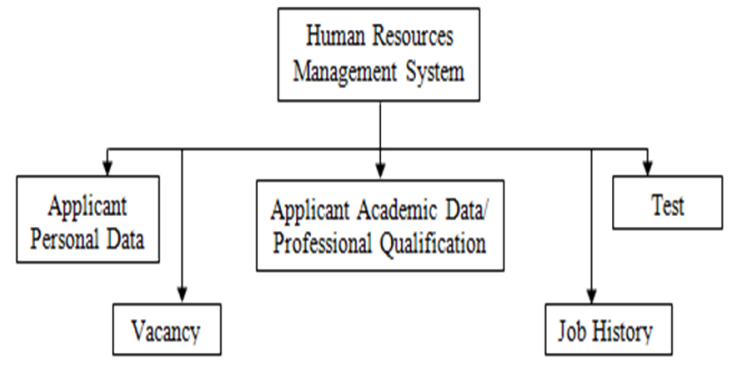

Fig. 4. Global chart of the database design
The knowledge base provides specific domain knowledge (facts and rules) about the subject acquired from the domain experts. It is designed based on rules, which combined quantitative (structured) and qualitative (unstructured) knowledge/information and it serves as the information store for the operational data that are to be processed. It contains information about the prospective job applicant and the job requirements as are sent by the establishments employing the services of job bureau. The knowledge base of WBHRMS contains two major inter-related databases, namely: job requirement database, applicant database and other databases (Ifeta, 2006). The illustrative architecture of the proposed knowledge based system for job procurement is conceptualized in figure 3 .

In the database, the entire knowledge base can be conceptualized as a network of relations. A relation is a two-dimensional table that has a number of rows and columns. It is synonymous with the 'file' concept in the conventional data processing environment. The database objects are conceptualized using a relational database model. A relation is similar to what is customarily referred to as a file and it is generally represented by a set of structured tuples. Each tuple of a relation corresponds to a record in a file and attributes correspond to fields within a record. The general form of a relation is given by

$$
\mathbf{R}\left[\mathbf{A}_{1}, \mathbf{A}_{2}, \mathbf{A}_{3} \ldots \ldots . \mathbf{A}_{\mathbf{K}}, \mathbf{A}_{\mathbf{K}+1} \ldots \ldots \ldots \mathbf{A}_{\mathbf{n}}\right] \text {, }
$$

where $\mathbf{R}$ represents the name of the relation, and the set $\left\{\mathbf{A}_{\mathbf{i}}\right\}, \mathrm{i}=1,2,3 \ldots, \mathrm{n}$, represents attributes of the relation $\mathbf{R}$ (Codd, 1970). A role-based mechanism is built into the system to specify access rights to the database system.

The web-based human resource management system has six relations in its knowledge base. The first five relations contain structured information, while the last relation contains unstructured information modeled in a relation using indicator of performance. The relational database supported by the system includes: 


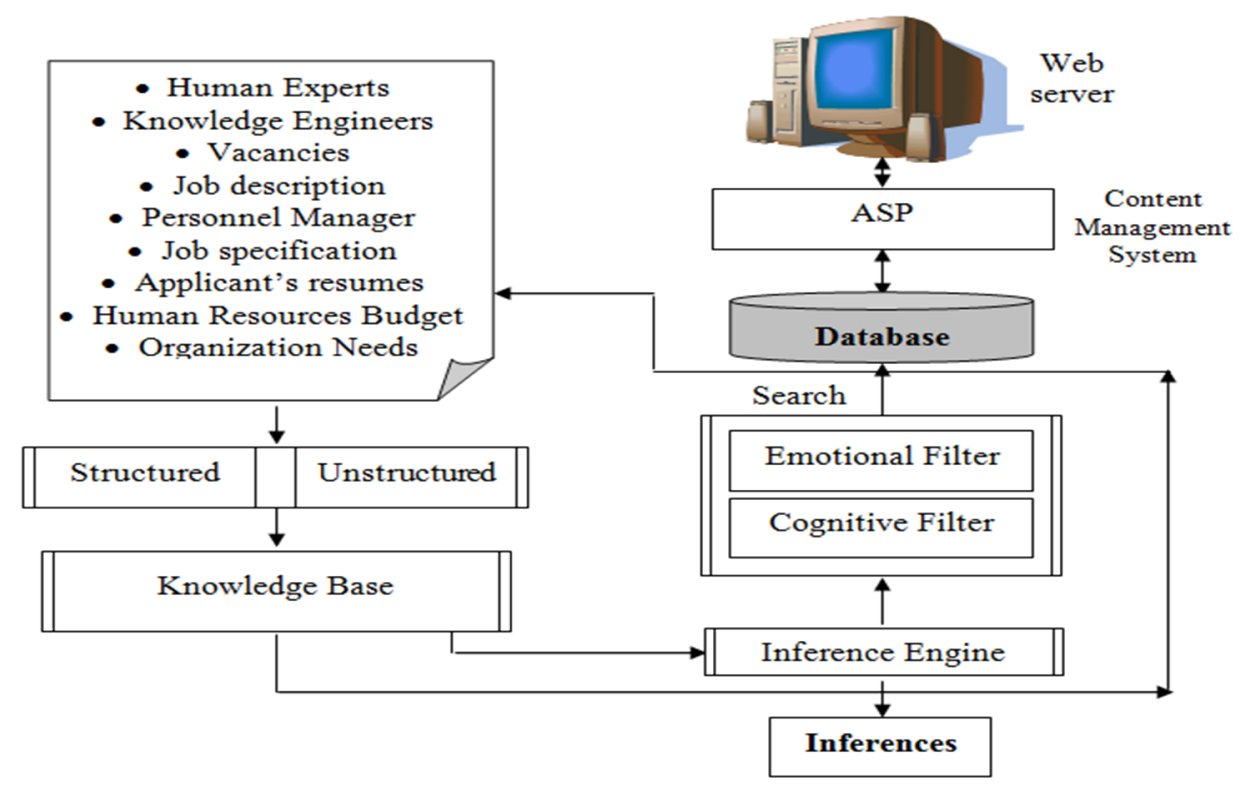

Fig. 5. Illustrative Architecture of the Proposed Knowledge Based System

i. $\quad$ APPLICANT-PERSONAL-DATA [applicant no, surname, other names, dateof-birth, sex, nationality, state-of-origin, marital-status, next-of-kin, age, address, email,

\section{ii. APPLICANT-}

ACADEMIC/PROFESSIONAL-

QUALIFICATION [applicant no, date of award, certificate, place-of-award, major subject, minor subject, class-of-award, name, pdate of award, pstatus].

iii. APPLICANT-JOB-HISTORY [applicant no, date employed, date disengaged, job code, status, employer, last-salary, condition for leaving, name, promotion, development, leaves, medical, min year].

iv. ORGANIZATION [organization no, address, telephone-no, line-of-trade].

v. JOB REQUIREMENT [job code, degree, status, sex, age, nationality, years of experience, job status of the organization].

vi. JOB VACANCY [organization no, job code, job title, vacancy, email].

vii. PERFORMANCE [applicant no, job-code, physical-test, intelligence-test, aptitudetest, score].

The inference engine (IE) provides the reasoning ability that enables the expert system to form conclusions from specific facts and rules about the subject provided by the knowledge base. The applications server would receive request/resumes from different applicants and sends it to them to the corporate server for heavy processing tasks. This module does the actual searching for and matching of applicant's information/qualification against the job request. WBHRMS adopts backward chaining method of making inferences. The proposed system looks at a particular job request and then search for the set of applicants that meet the requests and score them accordingly. The results are later sent to the qualified applicants through their email addresses.

The knowledge about applicant is composed of the following:

i. Personal data.

ii. Academic and professional qualifications.

iii. Job history,

While the knowledge about the job is composed of the following:

i. Applicants' registration.

ii. Job and organization requirements.

iii. Job vacancy

In each of the phases below, the inferences drawn will lead to the matching of another phase. See figure 6 below. 


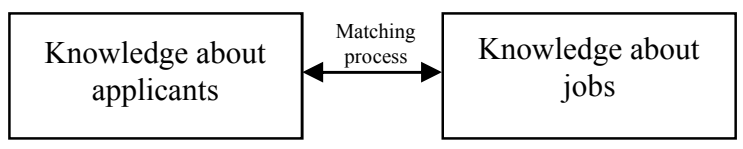

Phase I: The system studies applicants and jobs

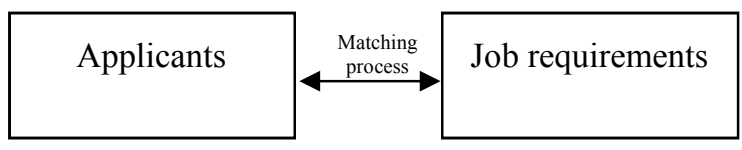

Phase II: Matching of applicants to job requirement.

\begin{tabular}{|c|c|c|}
\hline $\begin{array}{c}\text { Academic/ } \\
\text { Professional } \\
\text { qualifications }\end{array}$ & $\begin{array}{c}\text { Matching } \\
\text { process }\end{array}$ & $\begin{array}{c}\text { Job } \\
\text { requirements }\end{array}$ \\
\hline
\end{tabular}

Phase III: Matching of Academic/Professional qualifications with job requirement.

Figure. 6. Illustrate Architecture for the Matching System

The inference engine (IE) provides the reasoning ability that enables the expert system to form conclusions from specific facts and rules about the subject provided by the knowledge base with the corresponding decision variables of the job requirements knowledge and report a list of applicants that are selected for some specific jobs. Decision Support System (DSS) has two subsystems, namely cognitive and emotional filters.

The cognitive filter carries out series of reasoning, which include the inductive and deductive reasoning, on the information contents of the list of applicants appointable for a given job produced by the inference engine. For example, some steps could be taking in making decisions concerning the most suitable qualification and additional qualifications for a particular job, age limits for the job, working experiences in the areas related to the job, locations of the applicants, sex whether male or female, stature, status -whether married or not married, etc. All these could form the basis for cognitive filtering of the list of selected applicants as programmed by the system engineer.

The emotional filter carries out series of reasoning, which also include the inductive and deductive reasoning, on the information context of the list of applicants appointable for a given job produced by the inference engine. For example, a candidate could be preferred because of his relationship with the people in the authority; candidate could be disqualified because of bad behaviour, a male candidate could be preferred to his female counterpart because of the stress that is going to be involved, candidate might be disqualified on health ground, another one on tribe, etc. All these could form the basis for emotional filtering of the list of selected applicants as programmed by the system engineer.

The proposed system supports a user interface based on the interactive web browser known as internet explorer and access is gained by supplying username and password both of which aid the control of access to the website. The selection of each main menu leads to other sub-menus, which calls on inference procedure associated with that menu. The inference procedure is interactive and it guides intelligently to supply appropriate information. On selection of any of the menus, alternative matching decisions and reasoning behind the decisions will be presented to the expert. Finally, the system administrators will have the choice of applicants to match and recommendations will be made to human resources department of the firm/organization concerned. See the figure below. 


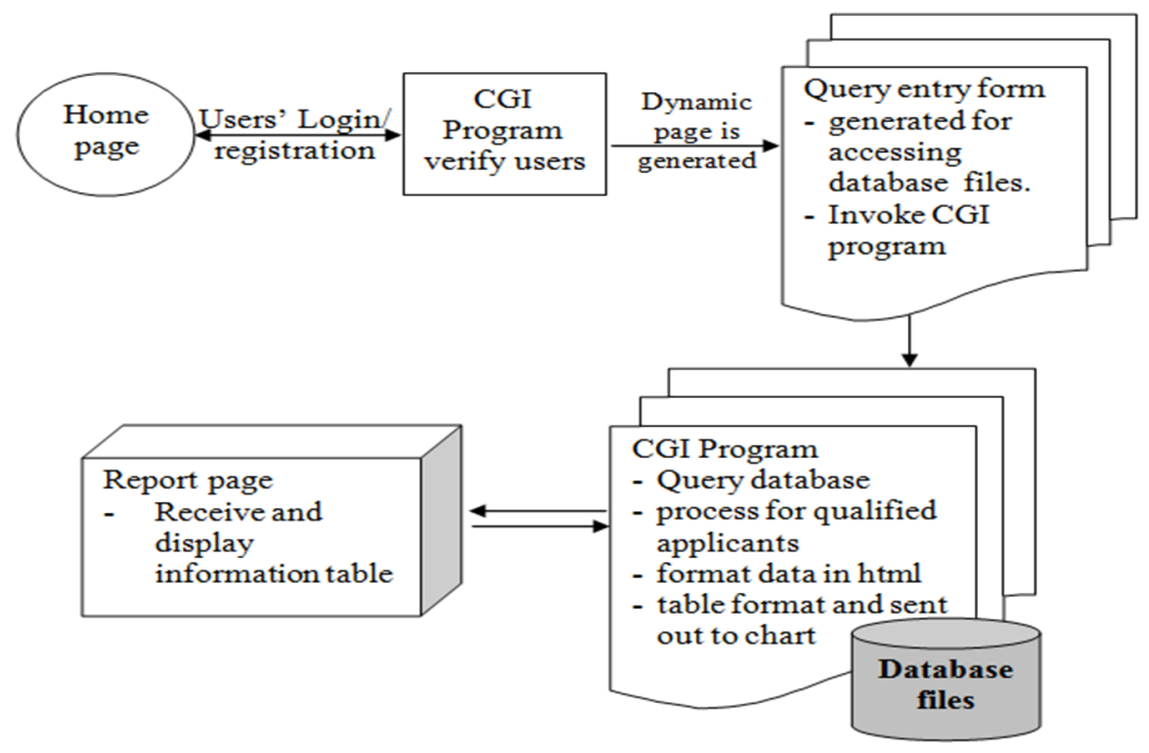

Fig. 7. Data Flow Diagram

\section{THE SYSTEM IMPLEMENTATION}

The use of Internet has moved from the old static view and download of information to more sophisticated dynamic use, such as e-commerce, egovernment and e-business. Any functioning site contains clients connected to server via network resources. The clients contain the browser, which display any information downloaded from the server. In addition, through the clients, information/data are uploaded to server for appropriate processing. In this regard, a website that could assist any organization to receive its applicant's data via internet is being developed. With this website, the applicants can search for organizations with vacancies and their addresses.
Having gotten any appropriate firm of interest, employment forms are made available for them to fill and submit, which are in turn uploaded to the organizations' server computers. Through an application developed in Internet Information Server, individual firm can then get connected to their server computers and retrieve the applicant data for processing.

Due to large flexibility of information delivery over the Internet, the system is implemented as a standard web-based application. The applicant side requires no more than standard Internet browser installed on the local machine which the main application functionality is assured by the server side. The basic component of the system infrastructure is presented in Figure 8. 


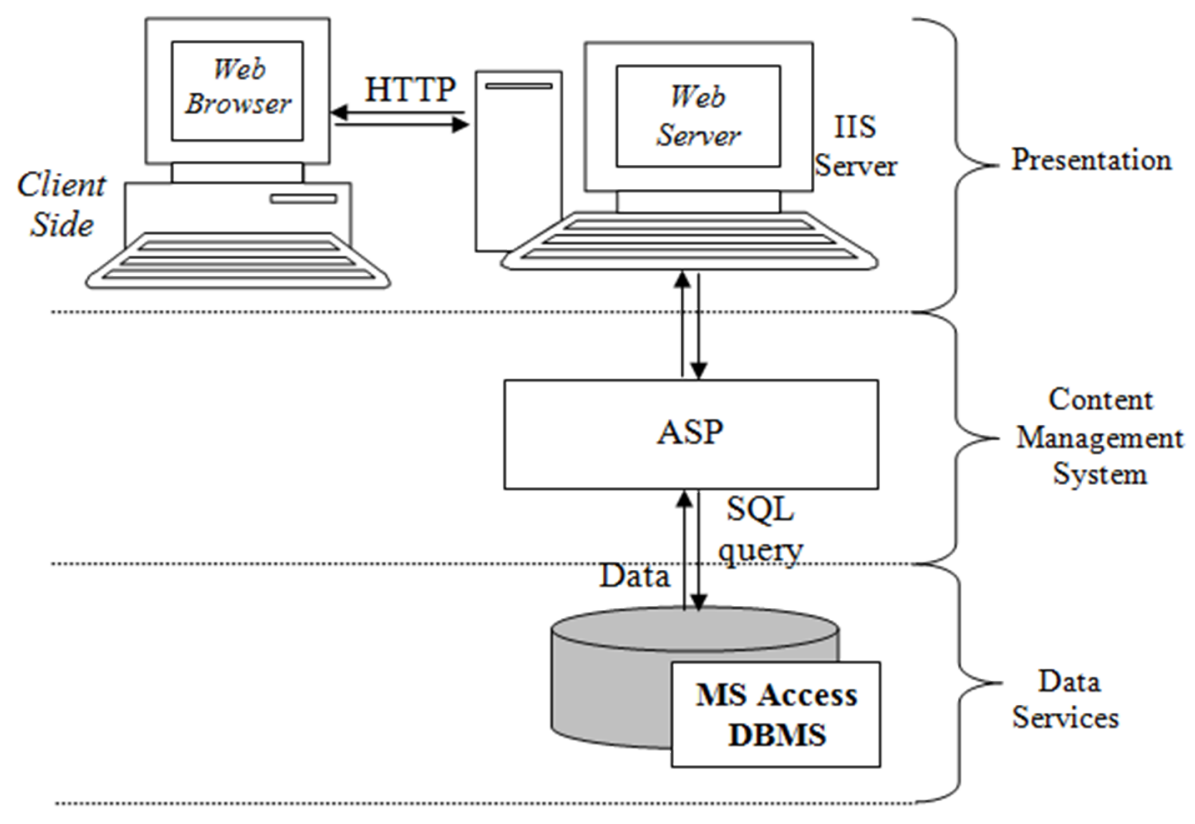

Fig. 8. Conceptual Diagram of the WBHRMS

The diagram in figure 8 is a three-layer Internet architecture which consists of presentation, content management system and data services. This architecture allows user to access the system through the Internet HTTP protocol and the user's request is transformed into a structure query language using an Active Server Page common content management gateway, which in turn passes it to the appropriate backend system. The common content management gateway provides a single point entry to the system via a URL. From the figure below, presentation consists of two main parts. The first part is the user interface to the system. User interface is based on HTML; so only browser such as internet explorer is required to use the system at the client (applicant) side. The second part is the Internet Information Server (IIS) web server. The content management system represents the interface between the presentation and data services. At the content management services, user's request is transformed into a structured query language where need be using ASP scripts. Data services represent database management system, and Microsoft Access is used to provide the required functionality. The system dynamically creates and returns an HTML page with the results of operation specified by the user to the browser.

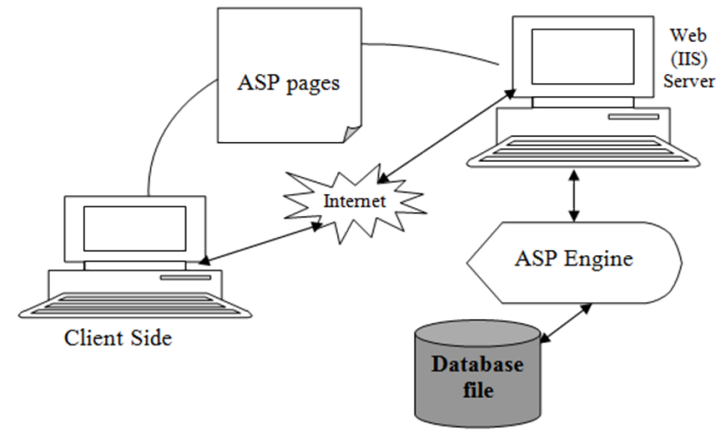

Fig. 9. The System Conceptual Architecture

Figure 7 and 9 show the data flow diagram, which includes one static HTML for home page (with forms for login to the system), and two CGI programs for performing authentication, and database accessing definitions. This diagram also serves as the web delivery design diagram.

\section{SECURITY}

The proposed system must be carefully secured from abuse and facilities must be put in place to ensure the security of the system against unauthorized use. In order to ensure that unauthorized transactions are not entered 
undetected the system will not allow any transaction or enquiry unless a user (company user) has logged on and entered the correct username and a password. Access will be denied to unauthorized users, who will be logged out after a predetermined number of trails. Each structure or staff is assigned a unique username and password, which is store in the administration part of the database. This prevents unauthorized access to the system. After a successful authentication, the main menu of the system will be loaded. Each applicant using the site will register and after registration username and password will be communicated through the email addressed submitted by such applicant. In addition, physical access to the computer system, diskette and auxiliary items should be restricted to authorized staff. There are adequate programmed controls on the facilities for system maintenance. For example where some data are becoming obsolete and unnecessarily occupying space on the system, provision is been made to remove such data. This will however only be done by authorized user.

\section{CONCLUSION}

The system would be of great importance in assisting human experts in solving problems associated to job procurement. It has definitely replaced the traditionally manual components of background investigation by providing an automated data retrieval process in order to make effective and timely decisions. The knowledge engineer uses the knowledge obtained from human experts to design the system package and draw inferences based on some rules concerning the static and dynamic data contained in the data bank. This would enables the main objective of the site which is to build a web-based system that will assist the human resources department in procuring staff without necessarily going through the rigours and problems associated with the conventional manual method of procuring staff, to be achieved. The research developed a neural network webbased human resource management system model (NNWBHRMSM) that has solved the problems associated with the past researchers especially, the one pointed out in Ogunwale, (2005), that is, inability to handle employment planning, reports, salaries and wages. Finally, the system NNWBHRMSM, which addresses performance, based on aptitude and intelligence tests is a promising one.

\section{REFERENCES}

[1] AKINTOLA, K. G., 1995, Knowledge Based Application System for Matching Applicants to Job: B. Tech. Thesis. The Federal University of Technology, Akure, Ondo State, Nigeria.

[2] AKINYOKUN, O. C and UZOKA F.M.E, 1998, A prototype on Information Technology Based Human Resource System, http://www.journal.au.edu/mcim/jan00/uzoka.d oc

[3] AKINYOKUN, O.C, 2000, Computer: A Partner to human experts 23rd Inaugural lecture of The Federal University of Technology Akure, Nigeria.

[4] BIGANZOLI, E., BORACCHI, P., MARIANI, L. and MARUBINI, E., 1998, Feed Forward Neural Networks for the Analysis of Censored Survival Data: A Partial Logistic Regression Approach", Statistics in Medicine, 17, pp. 1169-1186.

[5] CODD, E., 1970, Relational Model for Large Shared Data Banks, Communication of ACM, Vol. 13, No. 6., pp377-387.

[6] ENCARTA, 2012, Microsoft Corporation. All rights reserved.

[7] IFETA, U. C., 2006, Design and implementation of a web based human resource management system (WBHRMS), H.N.D Project Report, Mathematics, Statistics and Computer Science Department, the Federal Polytechnic, Ado- Ekiti, Ekiti State.

[8] ISHIKAWA, M., 1996, Structural learning with forgetting, Neural Networks, Vol. 9, pp. 509-521.

[9] KOZMA, R., SAKUMA, M., YOKOYAMA, Y. and KITAMURA, M., 1996, On the Accuracy of Mapping by Neural Networks Trained by Back porpagation with Forgetting., Neurocomputing, Vol. 13, No. 2-4, pp. 295311.

[10] OGUNWALE, Y. E., 2005, Development of a web-based human resource management system: M. Tech. Thesis. The Federal University of Technology, Akure, Ondo State, Nigeria.

[11]SCHUMACHER, M., ROSSNER, R. and VACH, W., 1996, Neural networks and logistic regression: Part I, Computational Statistics and Data Analysis, 21, pp. 661-682. 
R.O. Akinyede and O.A Daramola / International Journal of Computer Networks and Communications Security, 1 (3), August 2013

[12] STUART, J. RUSEEL and PETER NORVIG, Artificial Intelligence A modern approach, Prentice hall, Upper saddle River, New Jersey 07458 Pages 4,5

[13]UZOKA, F. M. E., 1998, Knowledge Based System for Matching Applicants to Job: M. Tech. Thesis. The Federal University of Technology, Akure, Ondo State, Nigeria. 